\author{
Journal of Social Economics Research \\ 2022 Vol. 9, No. 1 pp. 1-9. \\ $\operatorname{ISSN}(e): 2312-6264$ \\ $\operatorname{ISSN}(p): 2312-6329$ \\ DOI: $10.18488 / 35 . v 9 i 1.2129$ \\ (C) 2022 Conscientia Beam. All Rights Reserved. \\ check for
updates
}

\title{
WOMEN'S LABOR MARKET PARTICIPATION IN BANGLADESH: A LOGISTIC REGRESSION ANALYSIS
}

\author{
Md. Rashedus Salekin \\ Sabbir
}

Bangladesh University of Professionals, Bangladesh. Email: salekinsabbir3440@gmail.com Tel: +8801919472084.

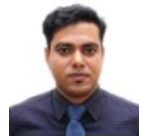

ABSTRACT

As women around the world struggle for equality, there is a need for measuring their progress. The problem regarding women's employment is more acute in Bangladesh. The conservative nature of Bangladesh's society is a significant obstacle in the achievement of their goals in life. The aim of this study is to explore the factors that affect the empowerment of women and determine the factors significantly associated with women's labor participation in Bangladesh. The study represents the current condition of women participating in the labor market in Bangladesh. A total of 375 structured questionnaires were distributed and 188 usable questionnaires were returned. SPSS version 20.0 was used and the analysis was carried out using binary logistic regression and bivariate analysis. Logistic regression was used to determine the risk factors for women's labor participation. The findings revealed that women's labor market participation is influenced by age, education and their partners' education, as education is also an important factor that changes human behavior significantly. This study has also proven that women with higher levels of education have more employment opportunities.

Contribution/Originality: This study is one of very few which have investigated the labor market participation of women in Bangladesh.

\section{INTRODUCTION}

Bangladesh, being a developing country, has witnessed significant growth in recent decades in terms of women's participation in the labor market (Dale, Fieldhouse, Shaheen, \& Kalra, 2002). Generally, a country transmits the benefits of economic growth through their labor market, which is one of the most vital mechanisms utilized by governing bodies. In the last few decades, foreign companies have used Bangladeshi labor to supply their products. With popularity in the labor market, the unemployment rate has decreased and the country has been enjoying a stable economic growth ever since. Slowly, the distribution ratio between male and female labor has also shifted to a great extent. Traditionally, women have not get the scope to join the labor market in any industry due to various barriers from a socio-cultural perspective; women were only allowed to complete primary level education and were prohibited from enrolling in higher level education in colleges and universities (Hamdan, 2005). After gaining minimal knowledge, they would be married off to manage the household. The conservative nature of Bangladeshi society became a huge obstacle for women who wanted to achieve more in their lives. Society may have felt insecure regarding women's safety outside, and even inside, the workplace, and the perception of their capability in terms of making decisions or undertaking projects was negative. Financial institutions were also unwilling to 
provide loans or assistance, as they had similar viewpoints and questioned women's competence. However, despite the challenges faced, women continuously showed interest in having a career of their own and joined the workforce enthusiastically. However, even with global progress, the gender gap in labor markets persists in Bangladesh and men still hold more advantageous positions (Huyer, 2015). In the Bangladeshi economy, women are not considered as primary participants to the labor force due to traditional opinions on women's roles. Women from all over the country have proved themselves by gaining employment opportunities in several industries. The contribution of women to the economy gets overlooked due to the existence of gender discrimination in the gathering of data for national statistics. Hence, the work that women do for the country does not receive the proper recognition (Gibson et al., 2016). As a result, women are subjected to inadequate programs and policies set by the governing bodies. If the government does not receive accurate information on the number of women participating in the labor force, they cannot implement appropriate guidelines to ensure similar rights for both male and female workers. As a result, women, who are income poor, become the most deprived group. When women from extremely rural areas have the opportunity to work, a country's poverty rate reduces (Canning \& Schultz, 2012). Increasing participation from female citizens allows them to generate income and enables the society to empower its, in turn, change society's socio-economic perceptions (Moswete \& Lacey, 2015). With the active involvement of female workers in a country, the labor market's entire dynamics change and the economy's condition improves.

An interesting assumption can be made from the current scenario regarding the gender gap in South Asia's labor markets. In most of its regions, women's economic contributions is still not a resource that has been tapped and taken advantage of. At the same time, we can see that majority of the regions are suffering from extreme poverty. However, Bangladesh revealed a situation to the contrary, where women's participation in the labor force has decreased the poverty rate. However, if we look at the ratio of female to male employment in the market, female employment is still low in comparison, but in Bangladesh it is even lower than in other regions of South Asia (Khaliq, Khan, Akbar, Hamayun, \& Ullah, 2017). For instance, if a woman works at their husband's field or farm, they have similar level of autonomy as homemakers or housewives have. In contrast, independent women who have a source of income possess autonomy of a more significant level. Young, unmarried women are more inclined to join the labor market, and they have the opportunity to bring their families out of severe poverty. Such shifts in employment proportion among genders are bringing changes to the mindsets of the people in the community, but to completely change their minds will be a challenge, as there are certain norms in Bangladeshi culture which will act as an obstacle. People think that a married woman, or a woman who needs to support a household, has a lower chance to contribute to the labor force. The viewpoint is that women need to take care of the household chores as well as conduct the official tasks assigned to them. Women cannot perform well in such pressurized positions, thus bringing their proficiency into question. This situation becomes even tougher when it comes to women living in rural areas. The labor market creates the demand for female workers based on their age and qualification. It is necessary for women to think about how they can maintain a balance in their personal and professional lives. If they are married and also have a child at home, the dynamic will be very different. It is quite normal to assume that women who are single and women who are married cannot prioritize work in the same way. There is also a notion of how the family themselves perceive having female members as the breadwinners. There are many obstacles blocking access to the labor market, and this type of traditional society, such as in Bangladesh, gets a lot of criticism. This study highlights the importance of education in empowering women to join the labor force. This paper suggests further research to obtain sufficient knowledge related to the requirements that employers demand when employing female laborers. More specifically, these studies need to determine the causes of having a lower participation rate of women in casual employment that offers wages. In a formal workplace where a salary if offered, women are getting the opportunity to work or are interested in doing so. However, their presence in the informal sector is unsatisfactory. The employers do not give opportunity to women for informal job. Empowerment of women through labor market participation is an explicit outcome that is often acknowledged. Women obtain their 
deserved social status and value from their respective family members, yet the extent to which women can change perceptions within their families and challenge gender norms in this conventional society is still to be understood.

\section{LITERATURE REVIEW}

Bridges, Lawson, \& Begum (2011) concentrated their research on what role poverty level and norms related to gender play in the labor market conditions of Bangladesh. It can be debated that enriching women's involvement in the workforce contributes to economic growth and reduces the poverty level of a country. The improvement in gender norms and poverty rate of any country are two of the underlying reasons for including women in the labor force, yet this has not been fully explored. This study looked at different determinants of labor market consequences. The survey gathered information on how much households spend and consume during a year, in which sector the individual members are employed, and what their status in the workplace is. Furthermore, the respondents from poor households were more likely to become involved in the labor market compared to respondents from rich households, although the significance to women laborers particularly was not evident. On the other hand, it was observed that the jobs that offered daily wage rates were performed by laborers from households in extreme poverty, while individuals from richer households mostly had salaried jobs or were self-employed (Himanshu, Murgai, \& Stern, 2013). An interesting finding came from this analysis. The households with working men now tend to have women in the households who are more likely to participate in Bangladesh's labor market (Bertrand, Kamenica, \& Pan, 2015). However, this was not the case few decades ago. The men in society had a huge change in attitude towards women working outside the home. An employed man now tends to marry or live with a woman who also works in a formal environment. The gender norms are gradually reaching a place where it is acceptable for women to have a job. However, Bangladeshi culture and social customs still have a long way to go, especially where women from rural areas are concerned (Aminuzzaman, Baldersheim, \& Jamil, 2003).

Shamsuddin (2015) examined how a stipend programme for women can impact Bangladesh's labor market. The studies that were conducted previously mostly focused on short-term effects, such as the number of girls enrolling in secondary education, their attendance rate in school and their eagerness towards learning. However, this current study mainly focuses on determining the long-term impacts on the country's labor market participation rate. Bangladesh was one of the first initiators of innovative programmes targeting a healthy growth of women's involvement in the labor market, and it is not the only developing nation facing gender disparity, but its efforts to reduce the gender gap is applaudable as it shows that they care about the future of the labor force, and the benefits are becoming apparent. Islam \& Pakrashi (2020) explored the role that access to microfinance plays in the participation rate of female laborers in Bangladesh by introducing a new determinant that might have an influence on the labor market participation rate. Microfinance is an innovative establishment that was introduced to help develop rural areas and to help women living in these areas. Nowadays, it is normal for women and their spouses to work outside of the home. However, it is not a usual scenario in the rural areas of Bangladesh. Hence, the concept of microfinance was introduced to promote self-employment and motivate people to start their own businesses, which, in turn, will help the economy to grow. Since 1980, numerous microfinance institutions (MFIs) have been established in Bangladesh. These MFIs mostly follow the lending procedures of Grameen Bank (Hossain et al., 2019). Dale et al. (2002) attempted to search for the opportunities that women in Bangladesh and Pakistan have in the UK's labor market. These women (working in the UK labor market) were observed to be less involved in the labor markets. The numbers were presented from surveys conducted nationally, such as the Labor Force Survey (LFS). The participation rate may have shown as low when the survey was conducted, but it cannot indicate the changes that are likely to take place in the future for these women. In surveys and published papers in the UK, it was revealed that of the women between the ages of 16 and $59,74 \%$ are economically active; the percentage of women meeting the same criterion is only $30 \%$ for Pakistani women and $20 \%$ for Bangladeshi women. Education level and English fluency are two major factors that influence these numbers. Though education is a vital factor in 
reducing gender inequality, other factors such as labor productivity may also explain the current gender disparities (Mulwa \& Gichana, 2020). Bangladeshi and Pakistani women usually quit their jobs voluntarily when they get married, need to take care of their family and children, or if they have the opportunity to form a partnership or business on their own. Hence, the participation rates of young women in the labor markets are higher in these two countries than for older women. The investigation of the participation level of female in the labor market of Bangladesh was executed by Mahmud \& Bidisha (2018) on a different standpoint. They analyzed the structural changes in the economy and what factors determines the supply of labor. Bangladesh, as an economy, has seen an uprise in their rate of economic growth. The modification in the gender proportion of the country's labor market could be stated as a catalyst for such a stable growth rate. This traditional and conservative community has been shifted to a new arena of progress by having more motivated women in their labor market. Half of Bangladesh's population is women but a very small number represents their gender as actively earning members of society. Their participation rate increased by almost $12 \%$ from $24 \%$ to $36 \%$ over a period of 11 years (1999 to 2010). A rapid increase was witnessed in the years between 2005 and 2010. Where this rate increased for female citizens, it declined by $4 \%$ in the same years. Even in this modern age, a woman cannot just decide to get a paid job outside their home; several aspects comes along their decision (Rahman \& Otobe, 2005). Many previous studies have stated that several guidelines and policies have improved the number of women in the market. However, there are also many unfavorable consequences for female laborers. Employers simply hire them as they can pay women lower wage rates and salaries than their male counterparts. In this way, employers are getting women to perform similar duties to their male peers, but the cost is cheaper (Farré Olalla, Jofre Monseny, \& Torrecillas, 2020). It is also evident that women usually remain at the bottom of the chain and get the lower ranked jobs, even if they are of a high caliber and competency. Society's view is that "at least they have a paid job”, and this is a breakthrough and a step forward out of poverty. Furthermore, women gain independence and freedom in society as well as in their own homes. A general, less researched, area remains to find out the determining factors for greater female participation in the labor market. Why female laborers are more concentrated in the less productive industries of Bangladesh needs to be highlighted. We believe that a mere employment opportunity can become a catalyst for women to have autonomy rather than the nature of employment acting as a crucial element for their self-dependency.

\section{RESEARCH METHODOLOGY}

As our target respondents were female, we primarily selected women who participate in the labor market. A total of 375 structured questionnaires were distributed, and 188 usable questionnaires were returned. The linear logistic regression method was applied to determine the factors that affect labor market participation in Bangladesh. The variables used in this study are briefly described below.

\subsection{Response Variable}

Whether a woman works in the formal sector is used as the response variable. The response variable was dichotomous by dividing it into two categories - those who work and those who do not work.

\subsection{Explanatory Variable}

We used a total of six independent variables, namely respondent's age; respondent's marital status; respondent's education level; partners' education; partners' occupation, and division (location). To find the divisionrelated variation in working status, we include this categorical variable in this analysis. The six divisions are Chittagong, Barisal, Dhaka, Khulna, Rajshahi, and Sylhet. Aside from division, we included respondents' education levels and ages as explanatory variables along with partners' education and occupation. 


\subsection{Binary Logistic Regression Model}

For this model, we take individuals who succeed and others who fail.

$\mathrm{Y}_{\mathrm{i}}$ denotes the dependent variable for the $\mathrm{i}^{\text {th }}$ observation. $\mathrm{Y}_{\mathrm{i}}=1$ if the $\mathrm{i}^{\text {th }}$ individual is successful, and $\mathrm{Y}_{\mathrm{i}}=\mathrm{O}$ if the individual fails.

Suppose for each of the $\mathrm{n}$ individuals, $\mathrm{p}$ independent variables $\mathrm{X}_{\mathrm{i} 1}, \mathrm{X}_{\mathrm{i} 2} \ldots \ldots \ldots, \mathrm{X}_{\mathrm{ip}}$ are measured. The probability of success for the independent variables is assumed to be:

$P_{i}=\operatorname{Pr}\left(Y_{i}=1\right)=\frac{1}{1+\exp \left(-\sum \beta_{i} X_{i j}\right)}$

$1-P_{i}=\operatorname{Pr}\left(Y_{i}=0\right)=\frac{\exp \left(-\sum \beta_{i} X_{i j}\right)}{1+\exp \left(-\sum \beta_{i} X_{i j}\right)}$

Where $x_{i 0}$ and $\beta_{i}$ are unknown coefficients.

\subsection{Hypothesis}

The hypotheses are:

$H_{o}$ : There is no association between women's labor market participation and the independent variables (division, marital status, highest education level, partners' education, partners' occupation, and age).

$H_{1}$ : There is an association between women's labor market participation and all the independent variables (division, marital status, highest education level, partners' education, partners' occupation, and age).

\section{ANALYSIS AND FINDINGS}

\subsection{Respondents' Backgrounds}

Regarding the demographic information, we found that respondents with no education and who live in rural areas have more scope to engage with work, and for partners' education we see the same thing. Unmarried women, or women not living with a partner, have more scope to work than women who are married, living with a partner, widowed or divorced. When a woman's partner is a day laborer, factory worker or small businessman, they are more likely to work than their counterparts whose partners are professional workers.

Table 1. Demographic information of the respondents.

\begin{tabular}{l|c|c|c}
\hline & & \multicolumn{2}{|c}{ Respondent currently working } \\
\hline \multirow{2}{*}{ Variable } & & No & Yes \\
\hline Education & Category & Percentage & Percentage \\
\hline \multirow{4}{*}{ Marital Status } & No education & 61.7 & 38.3 \\
\hline \multirow{2}{*}{ Partners' Education } & Primary education & 71.1 & 28.9 \\
\cline { 2 - 4 } & Secondary education & 79.5 & 20.5 \\
\cline { 2 - 4 } & Higher education & 70.2 & 29.8 \\
\hline \multirow{2}{*}{ Partners' Occupation } & Not married & 33.5 & 66.5 \\
\hline & Married & 72.5 & 27.5 \\
\cline { 2 - 4 } & No education & 63.3 & 36.7 \\
\cline { 2 - 4 } & Primary education & 71.1 & 28.9 \\
\hline & Higher education & 75.9 & 24.1 \\
\cline { 2 - 4 } & Parmer/day laborer & 76.5 & 23.5 \\
\hline
\end{tabular}



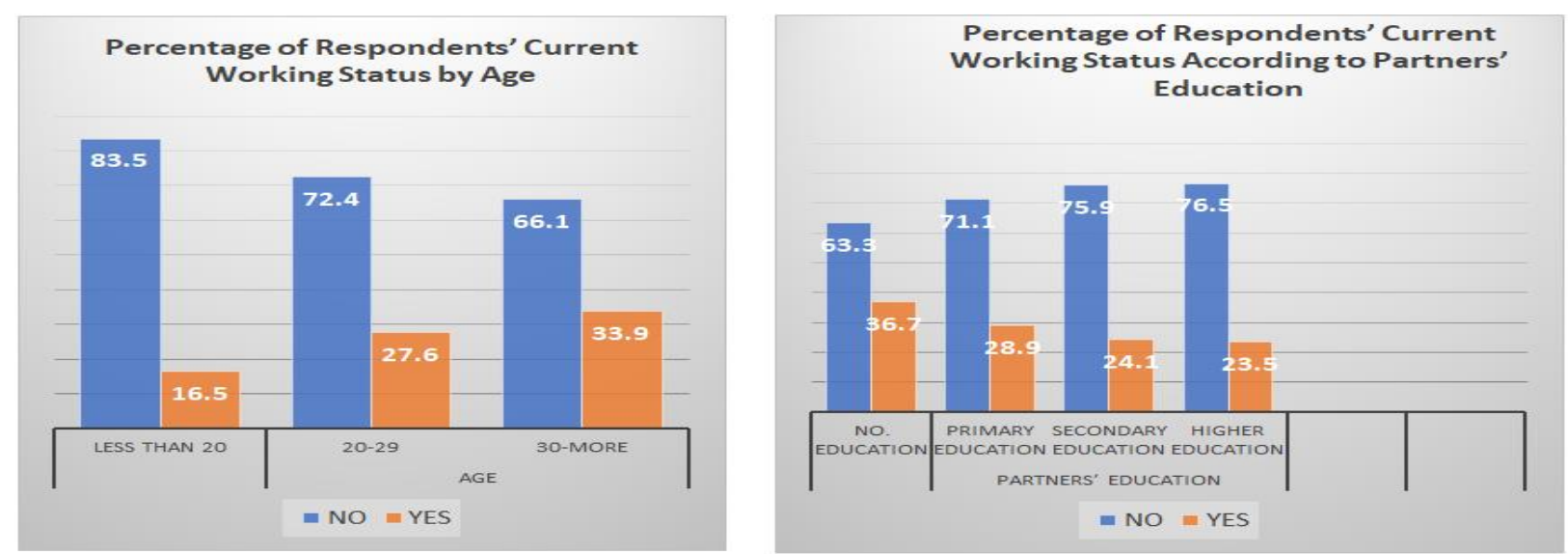

Figure 1. Percentage of respondents current working status, age, and partners' education.

From Figure 1, we see that when the age of the respondent is 30 or older, the employment rate is highest and for less than 20 it is the lowest. In addition, among married women, $27.5 \%$ are currently working and $72.5 \%$ are not.

\subsection{Test of Association}

Table 2. Significant level for variables.

\begin{tabular}{l|c|c}
\hline Independent Variable & Chi-square & P-value \\
\hline Age & 162 & 0.000 \\
\hline Division & 465.9 & 0.002 \\
\hline Highest education level & 205.6 & 0.000 \\
\hline Marital status & 257.8 & 0.004 \\
\hline Partners' education & 113.4 & 0.000 \\
\hline Partners' occupation & 6.366 & 0.032 \\
\hline
\end{tabular}

From Table 2, we can see that there is strong association between age, division, partners' education, partners' occupation, and marital status with women's employment.

\subsection{Binary Logistic Regression}

Table 3. Parameter estimates of binary logistic regression.

\begin{tabular}{|c|c|c|c|c|c|}
\hline $\begin{array}{l}\text { Independent } \\
\text { Variable }\end{array}$ & Category & $\boldsymbol{\beta}$ & Wald stat. & $\begin{array}{c}\text { Significance } \\
\text { Level }\end{array}$ & Odds ratio \\
\hline \multirow[t]{3}{*}{ Age } & Less than 20 & -0.739 & 45.629 & 0.000 & 0.478 \\
\hline & $20-29$ & -0.166 & 8.850 & 0.003 & 0.847 \\
\hline & $30+$ & & 46.364 & 0.000 & Reference \\
\hline \multirow[t]{4}{*}{ Education } & No education & -0.009 & 0.005 & 0.946 & 0.991 \\
\hline & Primary education & -0.245 & 3.547 & 0.060 & 0.783 \\
\hline & Secondary education & -0.481 & 16.147 & 0.000 & 0.618 \\
\hline & Higher education & & 52.133 & 0.000 & Reference \\
\hline \multirow[t]{3}{*}{ Marital Status } & Not married & 1.091 & 34.133 & 0.000 & 2.977 \\
\hline & Married & -0.611 & 40.050 & 0.000 & 0.543 \\
\hline & Others & & 139.756 & 0.000 & Reference \\
\hline \multirow{4}{*}{$\begin{array}{l}\text { Partners' } \\
\text { Education }\end{array}$} & No education & 0.699 & 37.185 & 0.000 & 2.011 \\
\hline & Primary education & 0.562 & 24.937 & 0.000 & 1.754 \\
\hline & Secondary education & 0.333 & 9.827 & 0.002 & 1.395 \\
\hline & Higher education & & 47.368 & 0.000 & Reference \\
\hline \multirow{3}{*}{$\begin{array}{l}\text { Partners' } \\
\text { Occupation }\end{array}$} & Farmer/day laborer & 0.122 & 0.809 & 0.368 & 1.130 \\
\hline & Professional worker & 0.283 & 2.408 & 0.121 & 1.327 \\
\hline & Others & & 2.503 & 0.286 & Reference \\
\hline \multirow[t]{6}{*}{ Division } & Chittagong & 0.430 & 19.551 & 0.000 & 1.537 \\
\hline & Barisal & 0.417 & 15.940 & 0.000 & 1.518 \\
\hline & Dhaka & 1.031 & 129.175 & 0.000 & 2.804 \\
\hline & Khulna & 1.290 & 184.194 & 0.000 & 3.634 \\
\hline & Rajshahi & 1.498 & 265.582 & 0.000 & 4.472 \\
\hline & Sylhet & 28 & 434.901 & 0.000 & Reference \\
\hline
\end{tabular}




\subsection{Taking the Decision to Reduce the Model or Not}

From Table 3 we can see that all the variables are significant except partners' occupation. Although it seems to have a significant effect on the employment of women, in this analysis it is found to be insignificant. We believe that the main reason for the insignificance of partners' occupation is that there are many missing observations for this variable. In making the decision to exclude the independent variables, we must focus on the special criteria that are significantly important in a statistical sense. Out of the six independent variables, we take five and apply the logistic regression, which reduces the form of the first stage of the logistic regression model.

Table 4. Reduced binary logistic regression model.

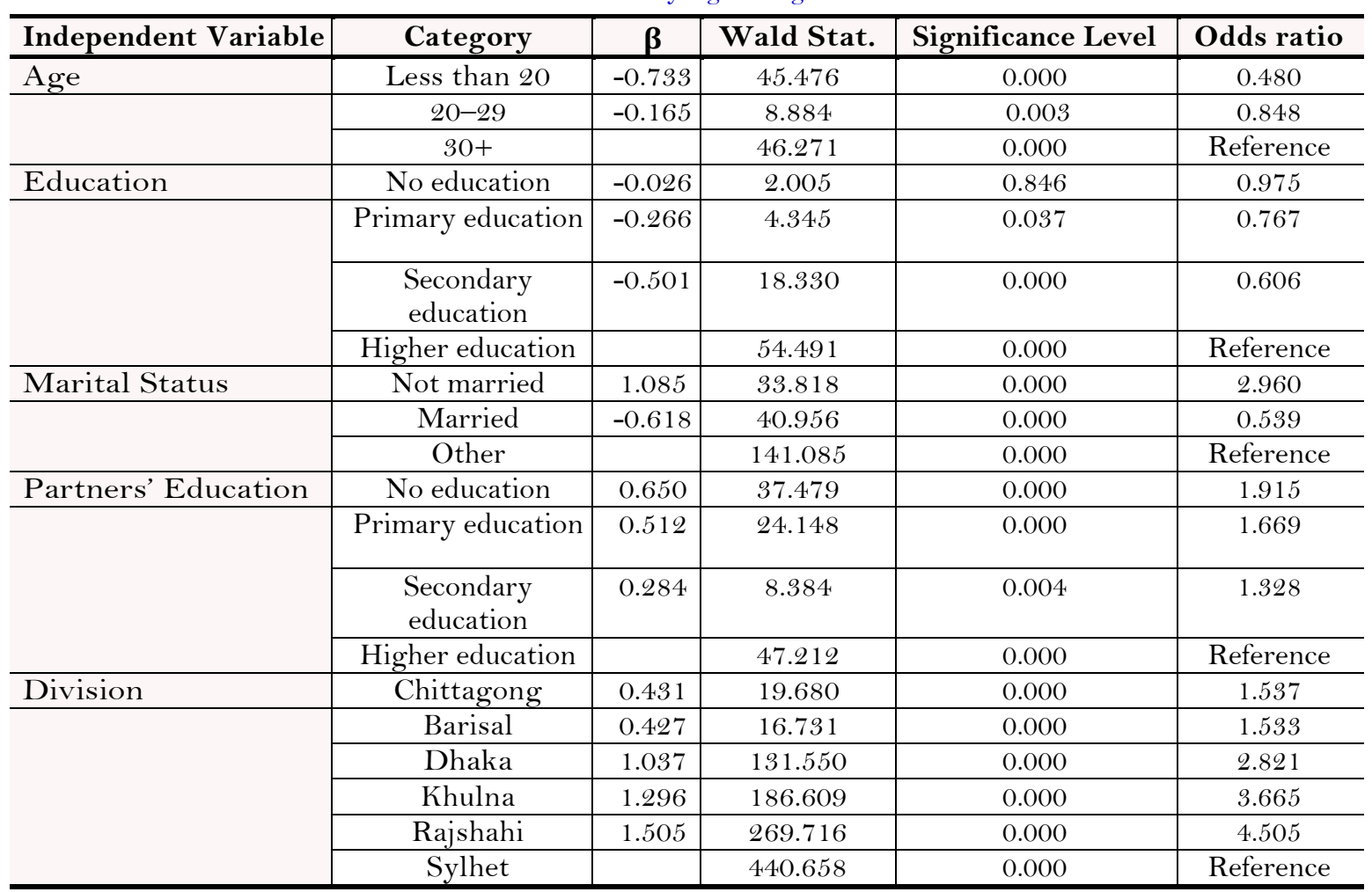

\section{DISCUSSION}

The female labor force contributes significantly to a country's economic development. The main goal of this research is to investigate the factors that influence female labor force participation. From Table 4, we see that the variables of age, division, partners' education, education level, and marital status all have a significant effect on women's employment. In general, the findings imply that education provides people with skills that improve human capital and raise people's chances of finding work. Education appears to compensate for the gender wage gap in the work force. As a result, our findings imply that education is an effective approach for reducing gender disparities in the job market. Education plays a vital role in this case as higher educated women have a wider scope to work; women with no education have $97.5 \%$ fewer opportunities; and for women with primary or secondary education, their scopes are $76.7 \%$ and $60.6 \%$ lower, respectively. Our analysis shows that employment for people in the under 20 age group and between 20 and 29 is $48 \%$ and $84.8 \%$ lower than the $30+$ age category, respectively.

In our study, we first include partners' occupation as a significant variable. From past studies, it was found that when husbands work, women are usually reluctant to work outside the home. Although it appears to have a major impact on women's employment in general, it is determined to be minor in this study. We believe that the lack of significance of the partners' occupation is due to many missing observations for this variable.

Employment for women who are not married, or not living with a partner, is 2.96 times higher than for those who are widowed or divorced. For women who are married, or living with a partner, employment is $53.9 \%$ lower, 
and when their partner has no education, women's employment is 1.915 times higher than those whose partner has completed higher education, and for primary and secondary education, those rates are 1.669 and 1.328 times higher, respectively. Among divisions, we found that employment in Rajshahi, Khulna, Dhaka, Chittagong, and Barisal is 4.505, 3.665, 2.821, 1.537, and 1.553 times higher than Sylhet, respectively. Women's engagement in the work force should be a priority for policymakers, even though significant progress has been made in increasing women's labor market participation rates.

\section{CONCLUSION}

The main objective of our study is to identify the factors that affect the employment of women in Bangladesh. Among all the independent variables, partners' education plays a vital role in this situation. If a man has no education, his wife must have a paid job for the sake of the family; this is why employment is higher for women whose husbands have no education. Age also has a significant impact on employment. Women who are at least 30 years of age have more experience than younger women, and married women who are aged 30 or older have more responsibility, so the rate of employment is higher for women who are at least 30 years of age than those who are under 20 or aged between 20 and 29. From this, we can see that the employment rate is highest among women with higher education levels. If we look at the employment rate by location, we can see that it is highest in Rajshahi and lowest in Sylhet. The findings of the study revealed that women's labor market participation is influenced by education, partners' education, and age. Women's employment in Bangladesh is also determined by sociodemographic factors. This study also proves that women who have achieved a higher level of education have more opportunities for employment.

\section{LIMITATIONS}

The study used a quantitative approach to analyze the data, but a qualitative approach could also provide deep insights, such as, face to face interviews or focus group discussions. The data used in the study were collected from primary sources, which may be inaccurate and therefore inadequate to perform a true analysis.

Funding: This study received no specific financial support.

Competing Interests: The author declares that there are no conflicts of interests regarding the publication of this paper.

Acknowledgement: This study received support from the Centre for Higher Studies and Research, Bangladesh University of Professionals, Bangladesh.

\section{REFERENCES}

Aminuzzaman, S., Baldersheim, H., \& Jamil, I. (2003). Talking back! Empowerment and mobile phones in rural Bangladesh: A study of the village phone scheme of Grameen Bank. Contemporary South Asia, 12(3), 327-348. Available at: https://doi.org/10.1080/0958493032000175879.

Bertrand, M., Kamenica, E., \& Pan, J. (2015). Gender identity and relative income within households. The Quarterly Journal of Economics, 130(2), 571-614. Available at: https://doi.org/10.1093/qje/qjvo01.

Bridges, S., Lawson, D., \& Begum, S. (2011). Labour market outcomes in Bangladesh: The role of poverty and gender norms. The European Journal of Development Research, 23(3), 459-487. Available at: https://doi.org/10.1057/ejdr.2011.14.

Canning, D., \& Schultz, T. P. (2012). The economic consequences of reproductive health and family planning. The Lancet, 380(9837), 165-171. Available at: https://doi.org/10.1016/s0140-6736(12)60827-7.

Dale, A., Fieldhouse, E., Shaheen, N., \& Kalra, V. (2002). The labour market prospects for Pakistani and Bangladeshi women. Work, Employment and Dociety, 16(1), 5-25. Available at: https://doi.org/10.1177/09500170222119227.

Farré Olalla, L., Jofre Monseny, J., \& Torrecillas, J. (2020). Commuting time and the gender gap in labor market participation. IEB Working Paper 2020/o3. 
Gibson, B. A., Brown, S. E., Rutledge, R., Wickersham, J. A., Kamarulzaman, A., \& Altice, F. L. (2016). Gender identity, healthcare access, and risk reduction among Malaysia's mak nyah community. Global Public Health, 11(7-8), 1010-1025. Available at: https://doi.org/10.1080/17441692.2015.1134614.

Hamdan, A. (2005). Women and education in Saudi Arabia: Challenges and achievements. International Education Journal, 6(1), $42-64$.

Himanshu, L., P., Murgai, R., \& Stern, N. (2013). Nonfarm diversification, poverty, economic mobility, and income inequality: A case study in village India. Agricultural Economics, 44(4-5), 461-473.

Hossain, P., Das Gupta, R., YarZar, P., Salieu Jalloh, M., Tasnim, N., Afrin, A., . . . Ahmed, S. M. (2019). Feminization'of physician workforce in Bangladesh, underlying factors and implications for health system: Insights from a mixedmethods study. PloS One, 14(1), e02 10820. Available at: https://doi.org/10.1371/journal.pone.0210820.

Huyer, S. (2015). Is the gender gap narrowing in science and engineering (pp. 85-103). UNESCO Science Report: Towards, 2030.

Islam, A., \& Pakrashi, D. (2020). Labour market participation of women in rural Bangladesh: The role of microfinance. The Journal of Development Studies, 56(10), 1927-1946.

Khaliq, A., Khan, D., Akbar, S., Hamayun, M., \& Ullah, B. (2017). Female labor market participation and economic growth: The cse of Pakistan. Journal of Social Science Studies, 4(2), 217-230.

Mahmud, S., \& Bidisha, S. H. (2018). Female labor market participation in Bangladesh: Structural changes and determinants of labor supply. In Structural Change and Dynamics of Labor Markets in Bangladesh (pp. 51-63). Singapore: Springer.

Moswete, N., \& Lacey, G. (2015). Women cannot lead": empowering women through cultural tourism in Botswana. Journal of Sustainable Tourism, 23(4), 600-617.

Mulwa, M., \& Gichana, T. (2020). Does education reduce gender differentials in labor market participation? A Kenyan perspective. African Development Review, 32(3), 446-458.

Rahman, R. I., \& Otobe, N. (2005). The dynamics of the labour market and employment in Bangladesh: A focus on gender dimensions. ILO Employment Strategy Papers, 13.

Shamsuddin, M. (2015). Labour market effects of a female stipend programme in Bangladesh. Oxford Development Studies, 43(4), 425-447.

The views and opinions expressed in this article are the views and opinions of the author(s). The Journal of Social Economics Research shall not be responsible or answerable for any loss, damage or liability caused in relation to/arising from the use of the content. 